\title{
A Viable Solution to Implementing Effective Instructional Supervision
}

\author{
Stephen Benigno ${ }^{1}$ \\ ${ }^{1}$ Texas A\&M International University, Laredo, Texas, USA \\ Correspondence: Stephen Benigno, Texas A\&M International University, Laredo, Texas, 78041-1900, USA. \\ E-mail: sbenigno@tamiu.edu
}

Received: November 16, 2015

Accepted: January 8, $2016 \quad$ Online Published: January 13, 2016

doi:10.5539/jel.v5n1p128

URL: http://dx.doi.org/10.5539/jel.v5n1p128

\begin{abstract}
With an increased emphasis on instructional accountability with respect to instruction, assessment and curriculum development, administrators have been struggling to find a model of supervision that is clinical and collaborative and that will produce an accurate assessment of classroom instruction. According to Goe (2007), "In recent years, the focus has moved away from holding schools accountable for student achievement and toward holding teachers accountable" (p. 12). The Clinical Supervision model is an accepted and viable strategy of teacher evaluation that has been utilized in many school districts for a number of years. Clinical Supervision, if conducted with fidelity, can provide the administration of the school with an opportunity to collaborate with the teacher and create an effective evaluation experience.
\end{abstract}

Keywords: supervision, clinical, evaluation, process, collaboration

\section{Introduction}

The Principal enters your room to discuss her observation of your class. It has been almost a week since she conducted the formal observation of the lesson and it has been on your mind all weekend! You have no idea what to expect from the meeting!

Researchers have indicated "that teachers hold the key to student achievement" (Cohen \& Hill, 2007; Darling-Hammond, 2010). That being said, the teacher evaluation process is critical and should not be a stressful, summative and conclusive exercise. It should not be a mystery or a subjective process involving only perception and or observation. The evaluation process should be an exercise that will encourage collaboration and participation. Danielson (2007) stated that "clear descriptions of practice enable teachers to consider their own teaching" (p. 6). It should be scientific, formative and based on specific criteria familiar to both the evaluator and the teacher. According Falender (2004) effective and reliable supervision requires the "ability to provide effective formative and summative feedback" (p. 778). The evaluation of the teacher should result in an ongoing formative process that will improve instruction in the classroom and encourage the teacher to participate in professional development. Toch (2008) added "as research has shown, the factor with the biggest impact on student achievement is the quality of the teacher in the classroom". (p. 77). Effective supervision of instruction can facilitate the development of an effective relationship between the teacher and the administration and that relationship can translate into quality instruction in the classroom.

\section{Current Strategies}

Much of the instructional supervision that takes place in the public school system is summative and specifically related to terminal teacher evaluations. Glickman, Gordon, and Ross-Gordon (2009), have indicated that "historically, supervision has involved inspection of teachers and is usually viewed as an instrument for controlling teachers" (p. 7). The evaluations are often the final interaction between the teacher and their supervisor prior to the ending of the school year. The evaluations are often conducted in the last stages of the school year. They are often poorly organized by both the teacher and the supervisor. Holland (2004) concluded that "in general and in spite of the best intentions, the process of teacher evaluation is fraught with mistrust, unclear goals and a lack of respect for the process and product" (p. 7). An opportunity for collaboration between the supervisor and the teacher with respect to the evaluation process is usually not adequately addressed in these expedited models of teacher evaluation. 
Many of the summative evaluation strategies involve the utilization of informal observations combined with a formal, pre-planned observation. The supervisor may attend the class, observe, take notes or use a check-sheet that contains pre-designated standards or objectives related to content expectations, instructional objectives, and adherence to standards or classroom management. And then again, the supervisor may not even observe the class and may only require a signature on a document that validates the teacher's effectiveness as an instructional leader. If the teacher is observed and an administrator does conduct an observation, the supervisor may or may not meet with the teacher and discuss the observation. An evaluation document is usually provided to the teacher after the observation. If the teacher does not approve of the evaluation they may be able to attach an addendum to the documents disputing the results of the process. The evaluation observation may be conducted again or the documentation may be submitted to personnel with the dispute document attached. Danielson and McGreal (2000) summarized that "Many educators regard teacher evaluation as an aspect of the profession of education that everyone must endure" (p. 9).

\section{The Clinical Model}

Clinical Supervision has been adapted by some educational entities as a viable process to enhance the supervision process and improve instruction. "Although there are multiple ways of observing, the clinical supervision model for conducting observations with teachers is relatively standard and accepted" (Glickman, Gordon, \& Ross-Gordon, 2014, p. 246). The process emphasizes planning and communication and the development of a formative and collegial relationship between the supervisor and the teacher. Borders and Brown (2005) described the supervision exercise as a process that should be a proactive, planned, purposeful, goal-oriented, and intentional activity.

The process of Clinical Supervision originated in the health industry and it has been described as "An exchange between practicing professionals to enable the development of professional skills" (Butterworth, 2001). Clinical Supervision is used in the health industry as a multiple step process that involves structure, guidance, collaboration and feedback within the specific context of the trainee's experience. Supervision has been defined in the health industry as "the provision of guidance and feedback on matters of personal, professional and educational development in the context of a trainee's experience of providing safe and appropriate patient care" (Kilminster et al., 2007, p. 2). The Clinical Supervision model can be and has been adapted effectively to teacher evaluation.

The process of Clinical Supervision can be an effective evaluation tool for Principals and it can also facilitate the instructional development process for the teacher. The key elements in the successful implementation of Clinical Supervision are the structured organization of the process and the collaboration between the individuals involved in the supervision. The focus of the model "is to create collegial relationships between school administrators and teachers, where authentic dialogue about teaching practice becomes the norm" (Downey et al., 2004, 2010).

\section{Orientation}

Initially, the process should be orchestrated collaboratively between the teachers and the supervisor. The "pre-observation" piece of the process should be discussed and explained to all teachers prior to the actual initiation of the exercise. The discussion can also be enhanced by including testaments from former teachers who have participated in the Clinical Supervision process. Teachers should be afforded the opportunity to participate in the discussion from the inception of the activity. Teachers should understand the purpose of the supervision activity and also be able to internalize and reflect on their responsibility in making the evaluation tool effective. Feedback should be solicited from the participants on a continual basis throughout the initial stages of the orientation process. Participant acceptance and confidence in the fidelity of the program will only enhance the effectiveness of the supervision activity.

\subsection{Pre-Observation Conference}

The collaborative involvement between the supervisor and the teacher begins with the pre-observation conference. The process should be explained and discussed in depth with the individual teachers again during the initial stages of the pre-observation conference. During the pre-observation conference, the supervisor and the teacher should expand their discussion concerning the role of the teacher in the activity. "These determinations are made before the actual observation, so that both the supervisor and teacher are clear about what will transpire" (Glickman, Gordon, \& Ross-Gordon, 2014, p. 247). The supervisor should encourage the teacher to discuss their perceived strengths and weaknesses as instructional leaders in the classroom. The different instructional strategies and communication style of the teacher should be discussed during this segment of the process. Assessment strategies, lesson planning and the context of the classroom may also be discussed during 
this conference. The conference should continue to be collaborative and engaging. The supervisor should avoid any judgmental statements or criticisms of the teacher or ideas expressed by the teacher.

Administrative communication and developmental supervision strategies are critical during this component of the clinical supervision process. The administrator conducting the observation and conference should understand and be able to implement specific behaviors that can facilitate the development of the conversation with the teacher. Listening and purposeful responses from the administrator conducting the supervision are critical in initiating and developing an effective collaborative relationship with the teacher. An analysis of the developmental level of the teacher should take place prior to the pre-observation conference. During prior observations, interviews, communication and analysis of the teacher, the teacher's level of expertise should be determined. The pre-observation conference should be tailored to meet the developmental level of the teacher. The dialogue of the conference should correspond with the developmental level and pedagogical understanding of the teacher to be observed. Novice teachers may need more direction and facilitation during the conference while others may be able to lead and facilitate the direction of the conversation.

The nature of the lesson and the formulation of the lesson will depend upon the topic of conversation between the administrator and the teacher involved in the activity. A prescriptive approach should be utilized during the formulation of the instructional plan to be implemented during the observation. The development of the observation activity will depend upon the teacher's experience, the documentation that has been gathered through formal or informal observations prior to the clinical supervision activity and the collaboration between the teacher and the administrator. The observation experience may require the teacher to present a lesson that may be prescriptive and specifically related to a competency within the standards (beginning teachers) or it may be a non-directional, "when the teacher or group is functioning at high developmental levels" (Glickman, Gordon, \& Ross-Gordon, 2014, p. 147), a demonstration of instructional pedagogy within the content area. The content of the lesson should involve multiple instructional strategies and the use of technology. The teacher should be encouraged by the supervisor, through collaborative communication, to differentiate instruction and address the multiple learners in the classroom. However, the direction of the lesson should be the result of a collaboration between the administrator and the teacher.

\subsection{The Observation}

The actual observation process should involve several documentation strategies. The utilization of technology to enhance and add objectivity to the observation is desirable. Strategic documentation should be extracted from the observation through multiple strategies and that documentation should be translated for interpretation purposes. Prior to discussing the observation with the teacher, the supervisor should review the documentation taken from the observation and make a determination as to the direction of emphasis of conversation with the teacher during the post observation conference. "Regardless of the instrument, questionnaire, or open-ended form used, the supervisor must make sense out of a large mass of information" (Glickman, Gordon, \& Ross-Gordon, 2014, p. 248). All documentation and notes should be made transparent and available for the teacher to review in advance.

\subsection{Post Observation}

The most critical and most difficult aspect of the supervision process is the discussion regarding the actual performance of the teacher in the activity. The literature on school improvement and professional development emphasizes the building of organizational capacity through collegial interactions between teachers and supervisors (Leonard \& Leonard, 2003). The collaboration process between the supervisor and the teacher will continue after the observation and into the post-observation conference. The teacher should initially have the opportunity to self-evaluate and be able to express themselves regarding their performance during the conference. The teacher should be encouraged to review the documentation from the observation in advance. The post-observation conference should be a constructive interaction and include multiple opportunities for the teacher to participate in the conversation. All documentation taken from the observation process should be made transparent and it should be made available for interpretation and discussion by the teacher and the supervisor. An informal assessment of the exercise should be arranged after the post observation has been conducted. This informal interaction will give the teacher an opportunity to clarify some of the discussions that have taken place during the process. 


\section{Conclusion}

The utilization of the clinical supervision model may alleviate some of the anxiety related to the evaluation and assessment process. However, the responsibility for the success of the exercise will depend on the fidelity with which the supervisor and the teacher collaborate. This supervision process can be effective if it is implemented as part of a school wide process. The Clinical Supervision Model should be part of an overall supervision strategy that also provides an ongoing professional development and training for the teachers and the administrators within the organization. In conjunction with the Clinical Supervision Model, administrators should include multiple strategies for observing and monitoring instructional behavior in the classroom. Campus visibility, walk-throughs, interviews and collegial conversations with teachers and co-administrators will continue to facilitate an environment conducive to instructional improvement and collaboration among stakeholders. Clinical supervision, if conducted with the professional intention to improve instruction in the classroom can improve the supervisory capabilities of the administrator by establishing parameters for the evaluation process. These parameters can facilitate the design of a formative plan that will improve instruction in the classroom and help develop that necessary collegial relationship between the supervisor and the teacher.

It cannot be understated the importance of quality instruction in the classroom. However, the teacher alone cannot accomplish the tasks necessary to meet the needs of our students. The administration, supervisors, parents and community stakeholders must share in the responsibility. "By failing to produce meaningful information about instructional effectiveness, teacher evaluation systems severely limit the ability of schools and school systems to consider performance when answering critical questions or making strategic decisions about their teacher workforce" (Weisberg et al., 2009, p. 24). The authentic supervision of instruction can lead to improved instructional design and an authentic instructional and improved academic experience for the students in our schools.

\section{References}

Borders, L. D., \& Brown, L. L. (2005). The new handbook of counseling supervision. Mahwah, NJ: Lahaska/Lawrence Erlbaum.

Butterworth, T., Bell, L., Jackson, C., \& Pajnkihar, M. (2008). Wicked spell or magic bullet? A review of the clinical supervision literature 2001-2007. Nurse Education Today, 28(3), 264-272. http://dx.doi.org/10.1016/j.nedt.2007.05.004

Cohen, D. K., \& Hill, H. C. (2007, October). Instructional policy and classroom performance: The mathematics reform in California. In L. Goe (Ed.), The link between teacher quality and student outcomes. A research synthesis. Washington, DC: National Comprehensive Center for Teacher Quality.

Darling Hammond, L. (2010, October). Evaluating teacher effectiveness: How teacher performance assessments can measure and improve teaching. Retrieved from http://www.americanprogress.org/ssues/2010/10/pdf/teacher_effectiveness.pd

Danielson, C. (2007). Enhancing professional practice: A framework for teaching (2nd ed.). Alexandria, VA: Association for Supervision and Curriculum Development.

Downey, C. J., Steffy, B. E., English, F. W., Frase, L. E., \& Poston Jr., W. K. (2004). The three-minute classroom walk-through: Changing school supervisory practice one teacher at a time. Thousand Oaks, CA: Corwin Press.

Downey, C. J., Steffy, B. E., English, F. W., Frase, L. E., \& Poston Jr., W. K. (2010). Advancing the three-minute classroom walk-through: Mastering reflective practice. Thousand Oaks, CA: Corwin Press.

Falender, C. A. et al. (2004). Defining competencies in psychology supervision: A consensus statement. Journal of Clinical Psychology, 60, 771-785. http://dx.doi.org/10.1002/jclp.20013

Glickman, C. D., Gordon, S. P., \& Ross-Gordon, J. M. (2007). Supervision of instruction: A developmental approach. Boston: Allyn \& Bacon.

Glickman, C. D., Gordon, S. P., \& Ross-Gordon, J. M. (2014). Supervision and Instructional Leadership. A Developmental Approach (9th ed.). New Jersey: Pearson Education, Inc.

Goe, L. (2007). The link between teacher quality and student outcomes: A research synthesis. In National Center for Teacher Quality (p. 12).

Holland, P. E. (2004). Principals as supervisors: A balancing act. National Association of Secondary School Principals Bulletin, 88(639), 3-14. http://dx.doi.org/10.1177/019263650408863902 
Kilminster, S. M., \& Jolly, B. C. (2000). Effective supervision in clinical practice settings: A literature review. Medical Education, 34, 827-840. http://dx.doi.org/10.1046/j.1365-2923.2000.00758.x

Leonard, L., \& Leonard, P. (2003). The continuing trouble with collaboration: Teachers talk. Current Issues in Education, 6(1).

Toch, T. (2008, October). Fixing teacher evaluation: Evaluations pay large dividends when they improve teaching practices. Educational Leadership, 66(2), 32-37.

Weisberg, D., Sexton, S., Mulhern, J., \& Keeling, D. (2009). The widget effect: Our national failure to acknowledge and act on differences in teacher effectiveness.

\section{Copyrights}

Copyright for this article is retained by the author(s), with first publication rights granted to the journal.

This is an open-access article distributed under the terms and conditions of the Creative Commons Attribution license (http://creativecommons.org/licenses/by/3.0/). 